\title{
Correction to: Cellulose acetate, cellulose acetate propionate and cellulose acetate butyrate membranes for water desalination applications
}

\author{
Salah F. Abdellah Ali • Lovert A. William - Shaker M. Ebrahim • \\ Eman A. Fadl
}

Published online: 2 November 2020

(C) Springer Nature B.V. 2020

\section{Correction to: Cellulose}

https://doi.org/10.1007/s10570-020-03434-w

In the original publication, the author name "Shaker M. Ebrahim" was mistakenly omitted in the author group. The correct author group was provided in this correction.

Publisher's Note Springer Nature remains neutral with regard to jurisdictional claims in published maps and institutional affiliations.

The original article can be found online at https:// doi.org/10.1007/s10570-020-03434-w.

S. F. Abdellah Ali $(\bowtie)$

Chemistry Department, College of Science and Arts, Jouf

University, Al-Qurayyat, Saudi Arabia

e-mail: salah15egsalah15eg@yahoo.com

S. F. Abdellah Ali · L. A. William .

S. M. Ebrahim · E. A. Fadl

Materials Science Department, Institute of Graduate

Studies and Research, Alexandria University, Alexandria,

Egypt 